consideration; and further that the members of the Commission will not countenance a change in the Code which is both uncalled for and unnecessary, and which will render void much valuable work and threaten the success of the whole movement toward uniformity in zoological nomenclature. ${ }^{2}$

Witmer Stons
The ACademy of Natural Sciences,
Philadelphia,
May 7, 1912

$$
\text { "GENES" OR " GENS"? }
$$

AFTER discussing the significance of the word "phenotype" in Solence for April 26, Dr. O. F. Cook states that

Pluralizing the word "gen" is another diff. culty encountered by geneticists. Johannsen used the term mostly in its German plural form, Gene. Our writers have added another letter making a double plural, "genes," something like "memorandas."

This statement does not correctly represent the origin of the English word "gene" and its plural "genes," now generally used by writers of English papers on genetics. In Darwin's word "pangen" English usage renders the last syllable short, though the two halves of the word contribute equally to its meaning. When the word is transferred to the German, as has been freely done, a law of the German language makes both syllables long. On this account the German word "Pangen" better expresses the meaning involved than does the English word "pangen." Johannsen's word "Gen," like the last syllable of the German word "Pangen," from which it was directly de-

${ }^{2}$ Since the above was written I have read Professor Nutting's article in SCIENCE criticizing the powers of the commission and the difficulty of bringing a question of nomenclature before the congress for discussion. He fails to realize that these very facts give the code its strength and establish confidence in the permanency of nomenclature based upon it. We do not desire rules that appeal to this man or that, but rules that shall be permanent and the International Congress was perfectly right in making it as difficult as possible to change the code.-W. S. rived, is long in quantity. On transferring this happily chosen word to English it was desired to maintain the long quantity of the German word, and the addition of a final $e$, following a general law of English philology, was made simply for this purpose. The English word "gene" (pronounced gēn) is thus seen to bear no direct genetic relation to the German plural "Gene," and their likeness in spelling is purely a coincidence. The word "genes" is consequently not a double plural and not at all like "memorandas."

There is a further reason why the word "gene" should be preferred. This word must be used commonly in the plural form, but there is already a word "gens" in rather common literary use and having, at least sometimes, a genetic meaning.

Regarding the definition of "phenotype," few who carefully read the passage translated by Dr. Cook from Johannsen's book will agree with the translator that "phenotype" as used by its author was ever anything but an abstraction. "Centers among series of variations around which the variants are grouped" must always be abstractions, and yet they are, as Johannsen rightly says, " measurable realities." Every individual organism possesses an external appearance and a fundamental constitution, and is therefore a representative of some phenotype and of some genotype. The words "phenotype" and "genotype" were never intended to be limited to statistically investigated organisms. Statistical investigation may discover, measure and describe phenotypes, but it does not create them. Phenotypes and genotypes exist among Mendelian hybrids just as among all other organisms, and my use of the Mendelian categories to illustrate the proper use of these two words involves no "new version of phenotype."

Cold Spring Harbor, L. I., G. H. Shuld April 29, 1912

\section{CRYSTALLOGRAPHIO TABLES}

To the Editor of SoIEnce: The letter of Professor Oliver Bowles, of the University 
of Minnesota, which appeared in a recent issue of ScIENCE, ${ }^{1}$ opens up again the much discussed question of the presentation of the subject of crystallography to undergraduate classes.

Professor Bowles apparently takes the view that the fundamental laws of this science should be studied through their application to concrete examples. It has been the experience of the writer that, in general, the efforts of teachers of crystallography have not been directed with sufficient force to the lucid presentation of these fundamental laws. In spite of the many varieties of models in glass, wood, paper and plaster of Paris, now at the disposal of the modern teacher of this science, his classes often have only a vague notion of :

1. The mechanical relations of the directions of particle-attraction.

2. The all importance of symmetry as a basis of crystallographic study.

3 . The application of the above to crystallographic zones.

With regard to Professor Bowles's suggestion respecting tables for determination of axial ratios, the writer desires to point out that the use of such tables must of necessity presuppose the knowledge on the part of the student of which face of the crystal measured represents a unit plane. Taking the axial ratios of a number of common tetragonal minerals such as:

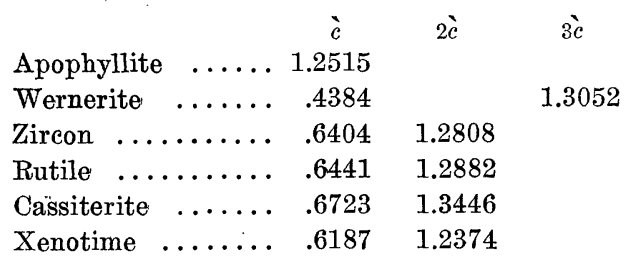

it will be readily seen that for each of these species a pyramid could be selected which would give a resulting axial ratio fairly close to some pyramid of each of the others. In point of fact, in the above series the difference in angle, measured from the prism, between the pyramid corresponding to 1.2374 (lowest value) and 1.3446 (highest value) is only $53^{\circ}$

${ }^{1}$ SCIENCE, April 12, 1912, pp. 576-577. -a difference not easy of determination with a contact goniometer in the hands of an inexpert student. Such instances could be multiplied many times.

In answer to Professor Bowles's first question as to whether tables of axial ratios would be useful as an aid to crystal determination with the reflection goniometer, it has been the writer's experience (and undoubtedly that of every crystallographic investigator) that in 99 cases the name of the species under investigation is known before it is set up for measurement. In the rare and much to be desired hundredth case (that of a new species) the name would obviously not appear in any table.

To the chemical crystallographer, tables of the axial ratios of artificial crystals might be of use could a work of sufficient size to include them all be prepared, but even such a collection of tables would have to be very frequently revised.

\section{H. P. WhitLock}

\section{Department of Mineralogy, New York State Museum, Albany, N. Y.}

To the Editor of Science: If we may judge from the character of most of the text-books on crystallography, Mr. Bowles's suggestion in SCIENCE for April 12, that any phase of this subject should be turned into an "illuminating and interesting exercise" is certainly a novel one. Yet surely the demonstration of the "value of the science as a means of mineral determination" is the ideal way to bring it before the student, so that crystals shall be to him more than, as Goldschmidt has put it," "a feared and hated collection of geometrical figures, of wood, plaster or pasteboard, with vertices and edges and bad Greek names, to be immediately forgotten on leaving school, and preferably never heard of again."

The writer has used tables similar to those described by Mr. Bowles for several years; thus far they have been mimeographed and handed around the class, but if elaborated and

\footnotetext{
${ }^{1}$ Ann. d. Naturphilos., IX., 121.
} 
collected into book form they would certainly be still more serviceable. The inclusion of all known minerals would be a very desirable feature, but the more important ones should be marked by bold-face type.

The necessity for repetition of each species would be in a large measure obviated if a complete discussion of the rules governing the orientation of crystals in general were presented. Even in the tetragonal system two values of $\dot{c}$ must be given unless the student is first taught to distinguish first from second order pyramids, by relative size of faces, presence of cleavage, direction of striations, etc. And in the more complex systems similar rules can be formulated. In fact, if such rules had only been collected and presented in an authoritative way in some text-book long ago the rather unfortunate confusion in the present usage in orienting even some common crystals-as, for instance, making the long prism-like faces of gypsum the pyramid-might have been avoided.

Yes, by all means, the preparation of such a list of tables should be undertaken. And perhaps it would be worth while to include similar tabulations of some of the physical properties of minerals, such as color, hardness, etc., on a more elaborate scale than those in Dana's text-book, for instance.

Edgar T. Wherry

\section{Department of Geology, LEHIGH UNIVERSITY}

\section{CHANGES OF BODILY FORM IN DESCENDANTS OF IMMIGRANTS}

To the Editor of Science: Four years ago Professor F. Boas, of Columbia University, was intrusted by the U. S. Immigration Commission with an investigation of the bodily characteristics of descendants of immigrants in America. The results of this undertaking were published two years ago in his report entitled "Changes in Bodily Form of Descendants of Immigrants" (Washington, 1910). In this report Dr. Boas questions the generally accepted theory of anthropologists that the form of the head is one of the most unchanging characteristics of human races, and concludes that it is subject to "far-reaching" changes in type due to the transfer of the races of Europe to American soil.

Last year I wrote a critique of this report entitled "Professor Boas's New Theory of the Form of the Head-A Critical Contribution to School Anthropology," ${ }^{1}$ in which I took the ground that Professor Boas's own figures do not warrant his conclusion that the shape of the head is influenced by a new environment.

In a recent number of ScIENCE ${ }^{2}$ there appeared a reply to my critique. As the general reader can not get a clear conception from this reply either of the nature of Boas's report of 1910 or of the salient points of my criticism of it, I venture to call attention to the following statements:

Professor Boas in his report of 1910 ignores all previous theories of this most complicated problem (see especially pp. $7,31,32,51$ ) and writes as follows:

Children born more than a few years after the arrival of the immigrant parent in America develop in such a way that they differ in type essentially from their foreign-born parents. These differences seem to develop during the earliest childhood and persist throughout life. It seems that every part of the body is influenced in this way; and even the form of the head, which has always been considered as one of the most permanent hereditary features, undergoes considerable changes. . . . The importance of this entirely unexpected result lies in the fact that even those characteristics which modern' science has led us to consider as most stable are subject to thorough changes under new environment. (This is quoted in the "Introduction" to the Report.)

The head form, which has always been consid ered as one of the most stable and permanent characteristics of human races, undergoes farreaching changes due to the transfer of the races of Europe to American soil (p. 7).

This fact is one of the most suggestive ones discovered in our investigation, because it shows that not even those characteristics of a race which have proved to be most permanent in their old home remain the same under our new surround-

\footnotetext{
${ }^{1}$ Published in the American Anthropologist, XIII., 1911, 394-436.

${ }^{2}$ April 5, 1912, 537-40.
} 